\title{
A desaceleração da economia da China e a transição para um "novo normal" no século 21
}

\author{
The slowdown of China's economy and the \\ transition to a "new normal" in the 21st century
}

DOI: $10.21530 /$ ci.v15n2.2020.1018

Rafael Henrique Dias Manzi ${ }^{1}$

Eduardo Viola ${ }^{2}$

\section{Resumo}

A China tem passado por profundas mudanças econômicas desde o fim da década de 1970 . As elevadas taxas de crescimento econômico transformaram a China de país pobre e agrícola em uma economia de renda média e industrializada no início do século 21. De todo modo, a partir da eclosão da crise global de 2008, a economia da China entrou em uma nova fase de relativa desaceleração e transição para um "novo normal", com taxas de crescimento econômico ao redor de $6 \%$. O principal objetivo deste artigo é examinar os fatores que explicam a desaceleração da economia da China no contexto pós-crise global de 2008. Os resultados apontam que a desaceleração da economia chinesa para um "novo normal" é um fenômeno esperado e reflete dinâmicas estruturais de um país que atingiu a renda média. Ao mesmo tempo, o aprofundamento dos desequilíbrios macroeconômicos e a perda de eficiência econômica evidenciam o esgotamento das políticas econômicas adotadas a partir da eclosão da crise global de 2008.

Palavras-chave: China; Economia Internacional; Novo Normal; Reformas Econômicas; Desequilíbrios Macroeconômicos.

1 Doutorado em relações internacionais, Universidade de Brasília (2018). É professor no curso de relações internacionais da Universidade Paulista e no mestrado profissional em desenvolvimento regional do Centro Universitário Alves Faria. ORCID: https://orcid.org/0000-0001-8518-8329; email: rafaelmanzi@hotmail.com

2 Doutorado em Ciência Política, Univ. São Paulo (1982), Pós-doutorado em Economia Política Internacional - University of Colorado at Boulder (1990). É Professor Titular (Concurso Público) do Instituto de Relações Internacionais da Universidade de Brasília desde 1993, aposentado desde agosto 2018, mas continua ativo na pós-graduação como Professor Sênior; Pesquisador 1 B do CNPq; ORCID: https://orcid.org/0000-0002-5028-2443; email: eduviola@gmail.com

Artigo submetido em 16/10/2019 e aprovado em 12/05/2020. 


\begin{abstract}
China has been undergoing profound economic transformations since the late 1970s. High rates of economic growth transformed China from a poor and agricultural country into an industrialized middle-income economy in the early 21 st century. With the outbreak of the 2008 global crisis, China's economy has entered a new phase of relative deceleration and transition to a "new normal" - economic growth rates around $6 \%$. The main objective of the article is to examine the factors that explain the slowdown of China's economy after the global economic crisis of 2008. The results show that the slowdown of China's economy to a "new normal" is an expected phenomenon and reflects structural dynamics of a country that has reached middle income after three decades of high rates of economic growth. At the same time, the deepening of macroeconomic imbalances and the loss of economic efficiency show the exhaustion of economic policies adopted since the outbreak of the 2008 global crisis.
\end{abstract}

Keywords: China; International Economy; New Normal; Economic Reforms; Macroeconomic Imbalances.

\title{
Introdução
}

Quando o ex-secretário geral do partido comunista chinês, Deng Xiaoping, iniciou as reformas econômicas no país, em fins dos anos 1970, a economia da China parecia não ter passado pelo processo de modernização produtiva que perpassou o continente europeu e expandiu-se ao redor do mundo ao longo dos séculos 19 e 20. Mesmo que tenha ocorrido elevação das taxas de crescimento econômico ao longo do período sob a liderança Mao Tsé-Tung, a renda per capita chinesa não teve impulso para iniciar um processo de convergência com os países desenvolvidos ou mesmo de industrialização recente do sudeste asiático. Esse quadro começou a reverteu-se a partir do início da década de 1980, quando a China iniciou uma série de reformas econômicas. Entre 1980 e 2008, o Produto Interno Bruto (PIB) da China registrou impressionante crescimento médio de $10 \%$ ao ano, com a aceleração dos processos de urbanização e industrialização. Nessa conjuntura, a China tornou-se, ao longo da década de 2000, uma economia de alta renda média semelhante ao status alcançado por outras economias de industrialização recente como Brasil, Malásia, México ou Turquia (Amsden 2004). 
A partir da eclosão da crise global de 2008, a China entrou em uma nova fase de relativa desaceleração econômica no contexto do "novo normal"3 da própria economia mundial. No caso da China, o novo normal é uma relativa desaceleração das taxas de crescimento econômico proposta, inclusive, pelas próprias lideranças de Pequim. Uma redução do crescimento para patamares ao redor de 6-7\% ao ano seria acompanhada de outros objetivos recomendados pelo governo da China: reduzir a dependência do investimento enquanto indutor do crescimento econômico; desenvolver novas tecnologias disruptivas e elevação da produtividade nos setores tradicionais; acelerar a transição da China para uma economia de baixo carbono nas próximas décadas e mais sustentável do ponto de vista ambiental.

O principal objetivo deste artigo é examinar essa conjuntura de relativa desaceleração da economia chinesa e a transição para um novo normal no século 21 . Argumenta-se que a redução do ritmo de expansão da economia chinesa ao redor de 6-7\% ao ano reflete dinâmicas estruturais de uma economia que atingiu um nível de renda média. Dessa forma, as políticas de estímulos fiscal e monetário implementadas pelo governo chinês a partir de 2008 suavizaram os impactos negativos da crise global de 2008. Contudo, essas políticas estão resultando no aprofundamento dos desequilíbrios macroeconômicos e com impactos negativos para os indicadores de produtividade da economia chinesa.

Do ponto de vista metodológico, o trabalho é construído a partir da identificação e análise das principais variáveis econômicas que explicam a performance da economia da China após a eclosão da crise global de 2008. No tocante aos desequilíbrios econômicos serão examinadas as principais variáveis de cunho macroeconômico (renda, consumo, poupança e investimento) ao longo da década de 2010. Essas análises serão combinadas com indicadores que mensuram, principalmente, os níveis de produtividade e eficiência econômica.

O trabalho está dividido em três seções. A primeira analisa os principais fatores que explicam a desaceleração da economia a partir do momento que o país tornou-se uma economia de renda média no decorrer dos anos 2000. A segunda descreve e examina as principais medidas adotadas pelas autoridades políticas da

3 O termo "novo normal" foi cunhado originalmente pelo analista de investimentos da PIMCO, Mohamed El-Erian, para contextualizar o cenário de menor ritmo de crescimento da economia global após a crise global de 2008, em comparação com a década de 2000. Em 2014, o próprio presidente, Xi Jinping, fez referência ao termo para contextualizar a conjuntura da economia chinesa ao longo da década de 2010 como "novo normal” e que essa relativa desaceleração da economia da China está dentro dos objetivos das autoridades de Pequim. 
China a partir da eclosão da crise global de 2008 e como essas medidas impactam os indicadores macroeconômicos e de eficiência da economia chinesa ao longo da década de 2010. Já a última seção discute o processo de reformas econômicas e as medidas adotadas pela administração Xi Jinping e os riscos, limites e desafios na transição para um novo normal da economia chinesa no século 21.

\section{A desaceleração da economia da China no pós-crise global de 2008: dinâmicas domésticas e externas}

A economia da China, a partir da eclosão da crise global de 2008, entrou em nova fase marcada pela redução do ritmo de crescimento do PIB em comparação com as décadas de 1990 e 2000. Na década de 2010, a taxa de expansão média do PIB da China declinou para uma média ao redor de $7 \%$ ao ano, como é possível observar na Figura 1.

Figura 1. Evolução da taxa de crescimento do PIB na China e em grupos de países selecionados

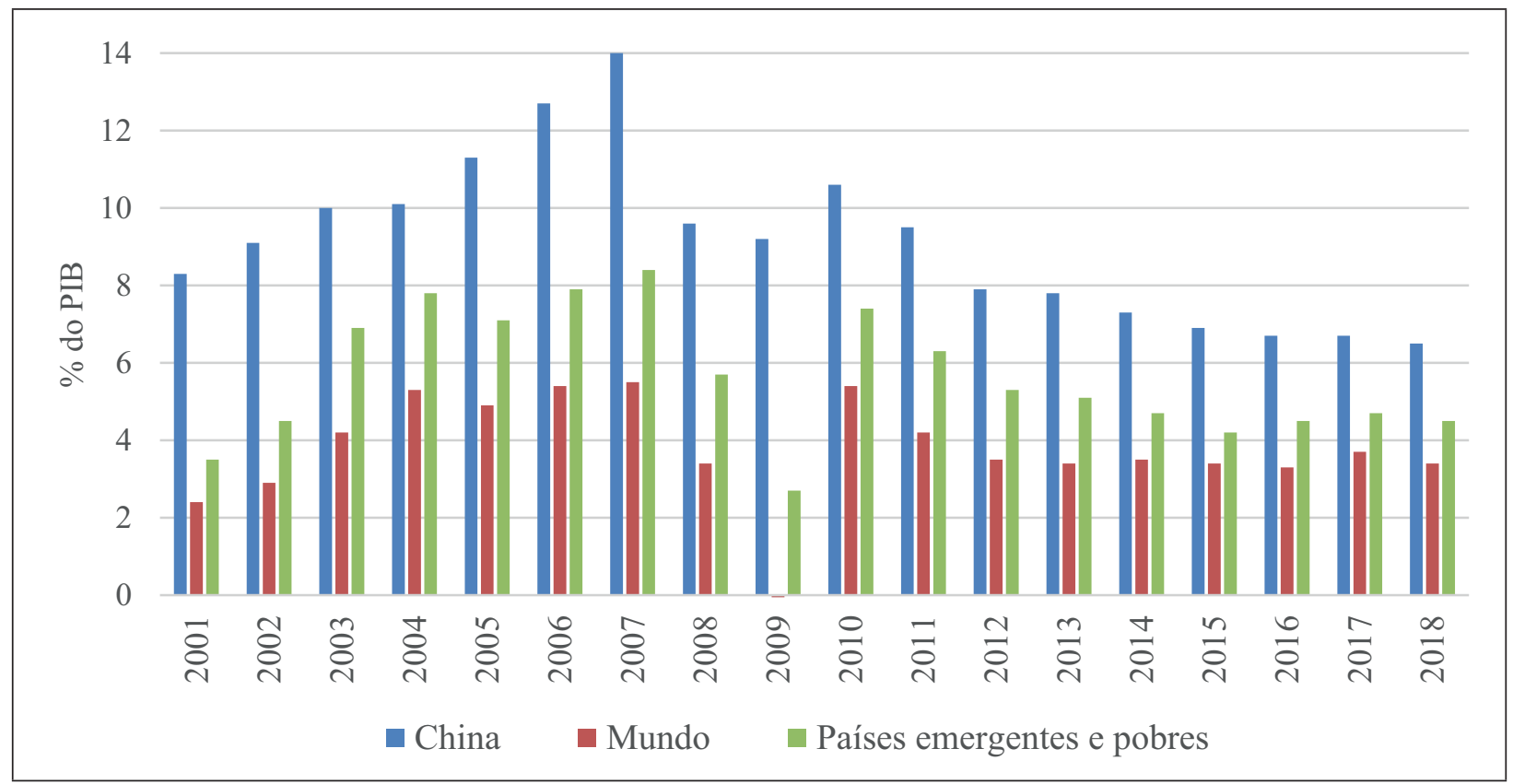

Fonte: Fundo Monetário Internacional — FMI (2019a)

A redução do ritmo de crescimento econômico da China no curto prazo não significa, por exemplo, que a economia chinesa esteja entrando em crise ou em uma nova fase de estagnação e baixo crescimento econômico. Pelo contrário, como observou o relatório de consultas mútuas entre o Fundo Monetário 
Internacional $(2015,1)$, “a China está em transição para um novo normal, com crescimento econômico mais lento, porém mais seguro e mais sustentável4". Essa desaceleração está relacionada a uma série de fatores e variáveis que podem ser resumidas na seguinte perspectiva.

Primeiro, o período de crescimento da população da China em idade produtiva - denominado de "bônus demográfico" - está chegando ao fim na década de 2010 e tende a acentuar-se nas próximas décadas. Dados do United States Census Bureau apontam que a população chinesa vai atingir o pico em 2020, quando o número total de habitantes do país vai ser próximo a 1.4 bilhões de pessoas. Apesar do crescimento absoluto da população até 2020, o número de habitantes em idade produtiva (15-64 anos) atingiu o pico já em 2015, em virtude da baixa participação de pessoas acima de 65 anos na China. Esse fenômeno é reflexo da redução das taxas de fertilidade da população chinesa ainda na década de 1970, ou seja, anteriormente à introdução da política de filho único, adotada oficialmente pelo governo chinês em 1985. Na Tabela 1 observa-se o início das mudanças demográficas na China a partir do começo da década de 2010 e que tendem a reduzir o número de trabalhadores em idade produtiva nas próximas décadas.

Tabela 1. Evolução da população da China por grupos de idade (em \% do total) e o número total de habitantes entre 2010 e 2050

\begin{tabular}{lcccc}
\hline & $0-14(\%)$ & $15-64(\%)$ & $65+(\%)$ & População total (em milhões) \\
\hline 2010 & 18 & 73.4 & 8,6 & 1.336 \\
2015 & 17.1 & 72.9 & 10 & 1.367 \\
2020 & 17.3 & 70.4 & 12.3 & 1.394 \\
2035 & 14.2 & 65 & 20.9 & 1.388 \\
2050 & 13.1 & 60.1 & 26.7 & 1.301 \\
\hline
\end{tabular}

Fonte: United States Census Bureau (2018).

Um segundo fator está ligado ao esgotamento do modelo de crescimento econômico baseado na transição de mão-de-obra, principalmente da área rural para as cidades. À medida que se acelerou o processo de urbanização ocorreu uma realocação dos trabalhadores do setor rural para o urbano. Segundo Canuto (2010, 43, tradução nossa)

4 China is transitioning to a new normal, with slower yet safer and more sustainable growth. 
Esses trabalhadores migraram de atividades em que a produtividade econômica era próxima de zero, como na produção para a subsistência nas áreas rurais, para atividades ligadas a produção de bens manufaturados com a geração de bens e serviços de maior valor agregado. Essa realocação de atividade ocorreu sem a necessidade de um aumento significativo no nível de habilidade dos trabalhadores ${ }^{5}$.

Um dos resultados da realocação dos trabalhadores do setor rural para o urbano foi um gigantesco aumento da produtividade da economia da China. Entre 1978 e 2007, a produtividade média da China cresceu a um valor próximo de $3.6 \%$ ao ano. Contudo, os ganhos de produtividade por meio da realocação de trabalhadores do setor rural para o urbano reduzem-se gradualmente à medida que o processo de urbanização reduz a própria disponibilidade de mão-de-obra do setor rural e resulta em aumento do custo do trabalho nas áreas urbanas. No caso da China, Zhu (2012) observa que o ponto de virada de Lewis ocorreu ao longo da década de 2000, quando os salários passaram a registrar elevação mais acelerada e reduziu a disponibilidade de mão-de-obra oriunda da emigração de trabalhadores do setor rural em direção as cidades chinesas.

Além da redução da produtividade devido às limitações naturais da realocação de trabalhadores da área rural para as cidades, a desaceleração da economia chinesa está ligada também às características de uma sociedade urbana que é mais intensiva no consumo de serviços. Com a aceleração do processo de urbanização existe uma tendência de crescimento da demanda por serviços, principalmente nas áreas urbanas que apresentam maior dinamismo econômico. Como o crescimento da produtividade do setor de serviços é mais lento em comparação ao industrial, a realocação de trabalhadores do campo para a cidade irá concentrar-se principalmente em atividades que envolvem a prestação de serviços ${ }^{6}$ (Babones 2011).

No caso da China, a participação da indústria no PIB nacional foi ainda maior do que os padrões normais, já que o governo da China adotou uma política de crescimento econômico baseada, em grande medida, na exportação de manufaturas. Assim, a participação da indústria no PIB, que era pouco superior a $20 \%$ no fim

5 These workers moved from occupations in which their psysical and monetary productivity was close to zero, as in production for subsistence in many rural area, to light-manufacturing production with much higher marked value, a more generally accomplished without the need for major increases in worker skills.

6 Em 2015, por exemplo, a produtividade média dos trabalhadores empregados na indústria era 20\% superior em comparação aos trabalhadores alocados no setor de serviços. 
da década de 1970, elevou-se para valores próximos a $40 \%$ em 2000, e atingiu o pico em 2006, quando correspondeu a aproximadamente $48 \%$ do PIB chinês. Desde então, a indústria começou a perder participação para o setor de serviços, que aumentou sua participação no PIB nacional de 40\% em 2004, para 48\% em 2014. (Banco Mundial 2019). É por esse motivo que, mesmo com menor crescimento econômico, o número de empregos criados na China desde 2010 tem superado as metas estabelecidas pelo governo central. Isso porque o setor de serviços é, aproximadamente, $30 \%$ mais intensivo em mão de obra quando comparado com o setor industrial (Roach 2015).

Um terceiro fator que está contribuindo para reduzir as taxas de crescimento econômico decorre de a China já ter se tornado um país de renda média. Quando um país atinge um nível de renda média existe uma redução natural da produtividade da economia e, por seguinte, do próprio crescimento econômico. Esse fenômeno está ligado ao fato de que, no estágio inicial de desenvolvimento, os países de renda baixa tendem a competir nos mercados internacionais produzindo bens que são intensivos em mão de obra e utilizam tecnologias importadas de baixo custo. Esse processo permite um crescimento acelerado da produtividade, em virtude do baixo custo que o país tem para desenvolver e adquirir tecnologias importadas. Contudo, ao atingir o nível de renda média, o crescimento da produtividade passa a depender cada vez mais do desenvolvimento de novas tecnologias que são mais dispendiosas devido à necessidade de maiores investimentos em educação ou mesmo em Pesquisa \& Desenvolvimento. Eichengreen, Park e Shin (2013) observam que a taxa de crescimento econômico desacelera quando um país atinge uma renda per capita em Paridade de Poder de Compra (PPC) ao redor de US\$ 15.100. A partir desse patamar a taxas de crescimento do PIB per capita reduz, em média, de 5,6\% para 2,1\% $\%^{7}$ ao ano. Os dados indicam que o PIB per capita em PPC da China atingiu um PIB per capita ao redor de US\$15.100 em 2015.

Um quarto fator está ligado à própria magnitude das taxas de crescimento econômico registradas a partir do início da década de 1980. Em virtude do elevado crescimento da economia da China ao longo da década de 2000, por exemplo, o crescimento econômico do PIB chinês, em 2014, adicionou um valor muito maior na economia do país em comparação a década de 1990. Isso porque, mesmo que

7 A Coréia do Sul, por exemplo, demorou 30 anos (1960-1990) para elevar sua renda per capita que era de aproximadamente $7 \%$ da norte americana, em 1960, para 33\% em 1990. Entretanto, o país demorou outros vintes anos para elevar sua renda per capita que era de um terço da norte-americana em 1990, para patamares próximos a $50 \%$ da renda per capita dos Estados Unidos em 2010. 
o crescimento ao longo da década de 2010 tenha estabilizado em um patamar ao redor de 6-7\%, por exemplo, o valor adicionado desse aumento de renda é muito superior ao observado nos anos 1990, quando o PIB cresceu em média próximo de $10 \%$ ao ano. É por isso que, mesmo ao crescer a uma taxa próxima de $10 \%$ ao ano nos anos 1990, a contribuição da China para o crescimento da economia mundial era inferior, em comparação aos Estados Unidos que registrou taxas de crescimento ao redor de $4.5 \%$ (Lardy 2019).

Por último, a redução do ritmo de crescimento da China é reflexo da própria desaceleração da economia global após a eclosão da crise global de 2008. Entre 2009 e 2018, por exemplo, o crescimento da economia global declinou para uma média de $3.3 \%$ ao ano. Esse desempenho é semelhante à média observada ao longo da década de 1990, mas aproximadamente $1 \%$ menor em comparação ao ciclo de expansão anterior (2001-2008). Com a desaceleração econômica da economia global a partir da eclosão da crise global de 2008 - em especial no mundo desenvolvido - o ex-secretário do tesouro dos Estados Unidos, Larry Summers, levantou a hipótese de que o quadro de estagnação da economia global decorria de fatores estruturais ou de uma estagnação secular8. Ou seja, a forte desaceleração econômica a partir de 2008 não é apenas reflexo da ressaca das dívidas do setor privado e público, mas também de fatores estruturais que reduziram o crescimento potencial do PIB global (Summers 2016).

As ações conduzidas pelos governos e bancos centrais nacionais das economias desenvolvidas impediram um virtual esfacelamento do sistema financeiro mundial, mas foram incapazes de promover um novo ciclo de expansão da economia global semelhante ao da década de 2000. A lenta recuperação das economias desenvolvidas ${ }^{9}$, em um cenário marcado por taxas de juros reais próximas de zero, riscos de deflação e a estagnação da demanda doméstica, sugere redução da eficácia da política monetária e a existência de fatores estruturais ${ }^{10}$ que diminuem

8 O termo estagnação secular foi cunhado originalmente pelo economista norte-americano Alvin Hansen para descrever a conjuntura da economia dos Estados Unidos no fim da década de 1930.

9 A dimensão da desaceleração econômica no mundo desenvolvido pode ser mais bem observado a partir da performance dos países do G7 (Estados Unidos, Japão, Alemanha, Reino Unido, França, Itália e Canadá). Entre 2000 e 2007, essas economias cresceram em média 2,2\% ao ano. Em contraposição, entre 2008-2015 o crescimento médio da economias do G7 declinou para $1.1 \%$ ao ano.

10 A redução da demanda por novos investimentos é um fenômeno das próprias transformações tecnológicas. A Apple e a Google, por exemplo, são duas das maiores empresas norte-americanas. Mas as necessidades de investimentos dessas empresas em ativos físicos são menores em comparação a empresas tradicionais em virtude das características das próprias empresas. A airbnb e a amazon são outros exemplos de empresas que reduzem a demanda por investimentos físicos como hotéis, shoppings e lojas que comercializam bens e serviços. 
a aceleração das taxas de crescimento do PIB. O relatório do FMI (2019b) sobre as perspectivas da economia global aponta uma taxa de crescimento dessa economia ao redor de $3 \%$ - menor valor desde a eclosão da crise global de 2008 .

Além da redução do ritmo de crescimento econômico, o cenário global no pós-crise global de 2008 é marcado também por uma forte desaceleração ou mesmo estagnação dos indicadores que mensuram os níveis de internacionalização das economias nacionais. Pela primeira vez desde a década de 1980, por exemplo, a expansão do comércio internacional é inferior ao próprio crescimento da economia mundial (Sharma 2016). Os fatores que explicam essa redução das taxas de crescimento do comércio internacional não decorrem apenas da desaceleração da economia global. Importante parcela da explicação para a desaceleração do comércio global está ligada ao surgimento de variáveis políticas. O ressurgimento de forças políticas nacionalistas no âmbito dos Estados nacionais, os impasses das negociações no âmbito da Organização Mundial do Comércio (OMC) constituem-se importantes variáveis que explicam a relativa estagnação do processo de globalização econômica. (Manzi 2019).

A redução do ritmo de crescimento da economia global e do próprio comércio internacional tem reflexos negativos para o desempenho da economia da China. Após a entrada da China na OMC, em 2001, as exportações chinesas tiveram um ritmo de crescimento anual ao redor de $20 \%$ até a eclosão da crise global de 2008. O crescimento das exportações chinesas decorreu, principalmente, da elevação da demanda externa nos países desenvolvidos - especialmente nos Estados Unidos - e da crescente participação da China nas cadeias produtivas do sudeste asiático (Morris 2009). Esse cenário de crescente interdependência econômica levou Ferguson e Schularick (2007) a cunharem o termo "chimerica"11, para definir as relações econômicas entre China e Estados Unidos a partir do início do século 21. A eclosão da crise global de 2008 não significou, em um primeiro momento, um processo de redução ou ruptura da interdependência econômica da China com a economia global, mas resultou em forte desaceleração dos níveis de internacionalização da economia mundial.

Com o início da administração Trump, as relações bilaterais entre China e Estados Unidos entraram em nova fase, marcada por crescente rivalidade. O governo estadunidense anunciou a adoção de uma série de sobretaxas sobre produtos

11 O termo "Chimerica” pode ser entendido como uma espécie de simbiose entre Estados Unidos e China no tocante as relações econômicas e foi fundamental para alavancar as taxas de crescimento da China e da própria economia global. 
importados pelos Estados Unidos advindos da China. No relatório de outubro de 2019, o FMI apontou uma série de mecanismos diretos e indiretos que as tarifas norte-americanas têm sobre a economia da China. Em termos econômicos, os impactos dependem, da adoção efetiva das medidas protecionistas nos próximos anos $^{12}$. De todo modo, as simulações demonstram que os impactos econômicos podem reduzir o PIB da China em até $2 \%$ do PIB em um horizonte de 5 anos. (FMI 2019b).

\section{Os desequilíbrios macroeconômicos no contexto do pós-crise global de 2008}

A existência de desequilíbrios macroeconômicos na economia chinesa não é um fenômeno que teve início somente a partir da eclosão da crise global de 2008 . As lideranças do Partido Comunista já concordavam com a necessidade de reformas econômicas que promovessem um crescimento econômico mais sustentável em longo prazo. O ex-premier chinês, Wen Jiabao, declarou, ainda em 2007, que o modelo de crescimento econômico do país era "inconstante, desequilibrado, descoordenado e insustentável” (Lardy 2012, 1, tradução nossa).

Com a eclosão da crise global de 2008, o modelo econômico baseado, em grande medida, na existência de crescentes superávits nas contas externas e no acúmulo de capitais esgotou-se por três motivos: (1) a recessão econômica nos Estados Unidos e Europa Ocidental resultou em forte queda da demanda por produtos estrangeiros, (2) aumentou a percepção de desconforto por parte autoridades econômicas da China na continuação do financiamento dos déficits externos dos Estados Unidos em virtude dos elevados custos econômicos que essas operações tinham para o governo chinês e (3) em virtude da própria magnitude da economia chinesa, era impossível manter as taxas de crescimento econômico a partir da contínua expansão da demanda externa (Ferguson e Schularick 2009).

Ainda em setembro de 2008, o governo chinês anunciou um pacote de estímulo fiscal de 4 trilhões de renminbi (US\$ 586 bilhões) para serem investidos na construção civil, infraestrutura (rodovias, ferrovias e aeroportos), saúde, educação, meio ambiente e inovação tecnológica, com o intuito de mitigar o

12 As estimativas do FMI baseiam-se nos impactos diretos que as sobretaxas tem sobre as exportações chinesas e nos reflexos indiretos que são caracterizados por reflexos sobre a confiança dos investidores, queda de investimento e redução dos indicadores de produtividade da própria economia da China. 
choque externo. Além das políticas de estímulos fiscais, o governo chinês adotou políticas de relaxamento para a concessão de empréstimos que culminaram em forte expansão do crédito doméstico. As políticas de expansão de crédito foram direcionadas não apenas para empresas estatais controladas pelo governo central da China, mas em grande medida, para as empresas públicas controladas pelos governos locais. O resultado dessas políticas foi um crescimento adicional dos empréstimos bancários em 2009 de 7.4 trilhões de renminbi - valor três vezes superior ao observado em 2008. Essas políticas tiveram impacto significativo sobre a oferta de crédito na economia chinesa em virtude do sistema financeiro chinês estar centralizado em operações bancárias controladas pelo setor público. As políticas de relaxamento de crédito perduraram, principalmente, entre 2009 e 2012, e resultaram em uma série de consequências para a economia chinesa (Lardy 2012).

Primeiro, assistiu-se a um aprofundamento dos desequilíbrios de renda e consumo em virtude do gigantesco aumento das taxas de investimento a partir da eclosão da crise global de 2008. Na década de 2000, os desequilíbrios de renda eram canalizados para um crescente aumento dos superávits externos da China com o mundo. Com a nova conjuntura de forte desaceleração da economia global, o excesso de poupança foi canalizado para o aumento das taxas de investimento, que comprimiu ainda mais o consumo do setor privado e exacerbou os desequilíbrios macroeconômicos da China $^{13}$. Nas palavras de Lardy (2012, 51, tradução nossa), “...o indicador mais claro de desequilíbrio da economia da China decorre da parcela extremamente baixa do consumo privado. A participação do consumo privado na China de 34-35\% do PIB em 2008-2010 é a menor em comparação com qualquer outra grande economia do mundo."14

Esse fenômeno pode ser mais bem visualizado a partir da contabilidade das contas nacionais da China. A taxa anual média de investimento da China, entre 1990 e 2002, foi de $37,2 \%$ do PIB, o que resultou em superávits nas transações correntes ao redor de $2 \%$ do PIB. Contudo, a diferença entre poupança e investimento elevou-se consideravelmente ao longo da década de 2000 em virtude dos crescentes superávits externos da China com o mundo. Esse fenômeno pode

13 A magnitude das taxas de investimento e poupança da China torna-se mais clara quando comparada com a média da economia global. A média da taxa anual de investimento na economia mundial, entre 2003 e 2008 , foi de $23,9 \%$ do PIB mundial enquanto a poupança global foi de aproximadamente $24,1 \%$.

14 ...the clearest indicator of imbalance in China's economy that emerges from the expenditure approach in the extremely low share of private consumption in GDP. The 34 to 35 per cent share of $2008-10$ is so far and away the lowest share of any major economy in the world. 
ser visualizado na Figura 2, que demonstra como o aumento da taxa de poupança traduziu-se em aumento expressivo dos superávits externos da China ao longo da década de 2000. A linha verde sinaliza a elevação dos resultados das transações correntes (linha verde e eixo vertical do lado direito) de 2,6\% do PIB em 2003, para 5,8\% em 2005, e $10 \%$ em 2007. A partir de 2009 ocorreu substancial redução dos superávits nas transações correntes, que estabilizaram em uma média ao redor de $2 \%$ do PIB. A redução do superávits nas transações correntes foi direcionada para um significativo aumento das taxas de investimento na economia da China. A taxa de investimento saltou de uma média anual de 40.2\% do PIB (2001-2008), para 46.2\% (2008-2017) (Mckay e Song 2012).

Figura 2. Evolução da taxa de investimento, poupança (coluna da esquerda) e transações correntes (coluna da direita) da China (em \% do PIB)

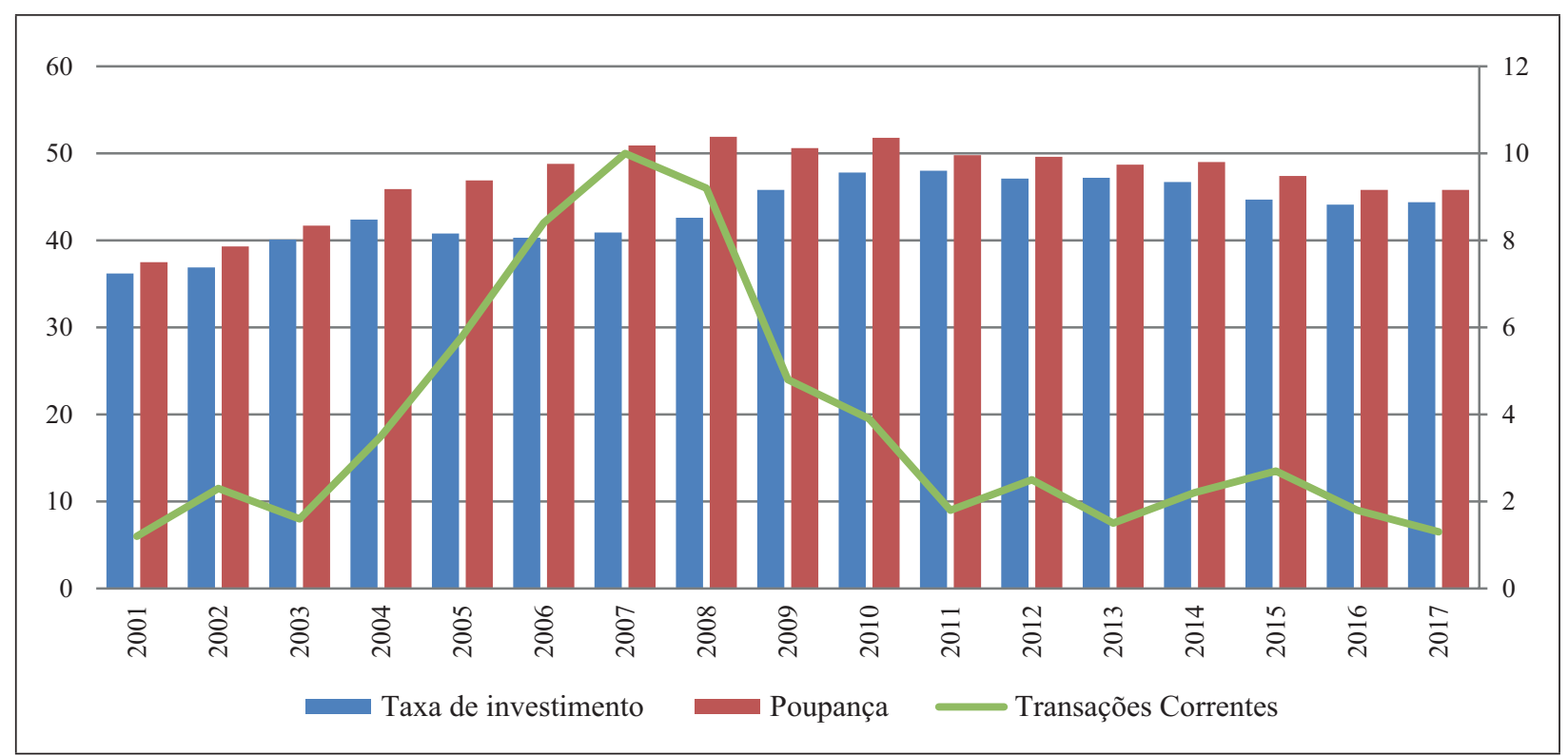

Fonte: Fundo Monetário Internacional — FMI (2019a)

Uma segunda consequência das políticas econômicas está ligada ao aumento da capacidade instalada e ociosidade da economia chinesa a partir da década de 2010. Como o aumento da expansão da capacidade produtiva (novos investimentos) não foi acompanhada por elevação na mesma proporção do lado da demanda houve uma redução da utilização da capacidade instalada principalmente do setor industrial. O aumento dessa capacidade é resultado, principalmente, da elevação dos investimentos realizados por parte das empresas estatais chinesas que acelerou-se no contexto pós-crise global de 2008 (Economy 2018).

Os dados do Relatório da Câmara de Comércio da União Europeia na China (2016), na Tabela 2, comparam as taxas de utilização de seis setores industriais 
da China em dois períodos distintos - 2008 e 2014. Como é possível notar, em todos os setores analisados houve redução da utilização da capacidade nos anos de 2008 e 2014. Em todos os setores industriais observados houve redução da taxa de utilização, principalmente nas indústrias do aço, refino e vidros planos ${ }^{15}$.

Tabela 2. Taxa de utilização em setores industriais da China em 2008 e 2014 (em \% da utilização da capacidade máxima)

\begin{tabular}{lllc}
\hline Produto & 2008 & 2014 & Diferença 2008/2014 \\
\hline Aço & $80 \%$ & $71 \%$ & $-9 \%$ \\
Alumínio & $78 \%$ & $76 \%$ & $-2 \%$ \\
Cimento & $76 \%$ & $73 \%$ & $-3 \%$ \\
Refino & $80 \%$ & $66 \%$ & $-14 \%$ \\
Vidro plano & $88 \%$ & $79 \%$ & $-9 \%$ \\
Papel & $90 \%$ & $84 \%$ & $-6 \%$ \\
\hline
\end{tabular}

Fonte: Câmara de Comércio da União Europeia na China (2016).

O desequilíbrio entre oferta e demanda não ficou circunscrito apenas ao setor de construção civil. A expansão de novos empreendimentos imobiliários e a redução do ritmo de crescimento na vendas de novos imóveis geraram descasamento entre oferta e demanda de imóveis no país que pode ser evidenciado a partir das seguintes palavras de Chen (2016, 16, tradução nossa):

Em 2014, as vendas de novas propriedades caíram 7,6\% em volume e 6,3\% em receitas, abaixo dos aumentos de $17,3 \%$ e $26,3 \%$, respectivamente, em 2013. Para piorar, o mercado imobiliário agora sofre com um excesso de oferta de imóveis. No final de 2014, a China possuía cerca de 75 bilhões de metros quadrados de novos imóveis em construção ou prontos para serem ocupados; mesmo que a demanda permanecesse estável, provavelmente levaria mais de cinco anos para vender todo esse espaço ${ }^{16}$.

15 A magnitude do consumo da indústria chinesa e do setor imobiliário do país é percebida quando se observa o percentual global de algumas matérias primas que são consumidas na China. Em 2015, a China consumiu aproximadamente $54 \%$ da produção global de alumínio, $50 \%$ da produção de níquel e $46 \%$ da produção de zinco. No caso de insumos utilizados pela indústria civil, o país é responsável por $57 \%$ da produção global de cimento.

16 In 2014, new property sales fell by 7.6 percent in volume and by 6.3 percent in proceeds, down from increases of 17.3 percent and 26.3 percent, respectively, in 2013. To make matters worse, the real estate market is now suffering from an excess of supply. At the end of 2014, China had around 75 billion square feet of new property space either under construction or ready to be occupied; even if demand were to remain steady, it would likely take more than five years to sell all that space. 
Terceiro, a expansão dos investimentos resultou em substantiva elevação do endividamento principalmente das empresas chinesas. O relatório do Mckinsey Global Institute (2015) apontou que as dívidas ${ }^{17}$ da China saltaram de US $\$ 7.4$ trilhões em 2007, para US\$28.2 trilhões no segundo semestre de 2014. Os dados do Bank International Settlements (2019) corroboram a percepção de um substancial aumento das dívidas na China. Entre 2008 e 2017, as dívidas na China saltaram de um patamar ao redor de $160 \%$ do PIB para 300\% como é possível observar na Figura 3.

Figura 3. Evolução das dívidas na China por setor (em \% do PIB)

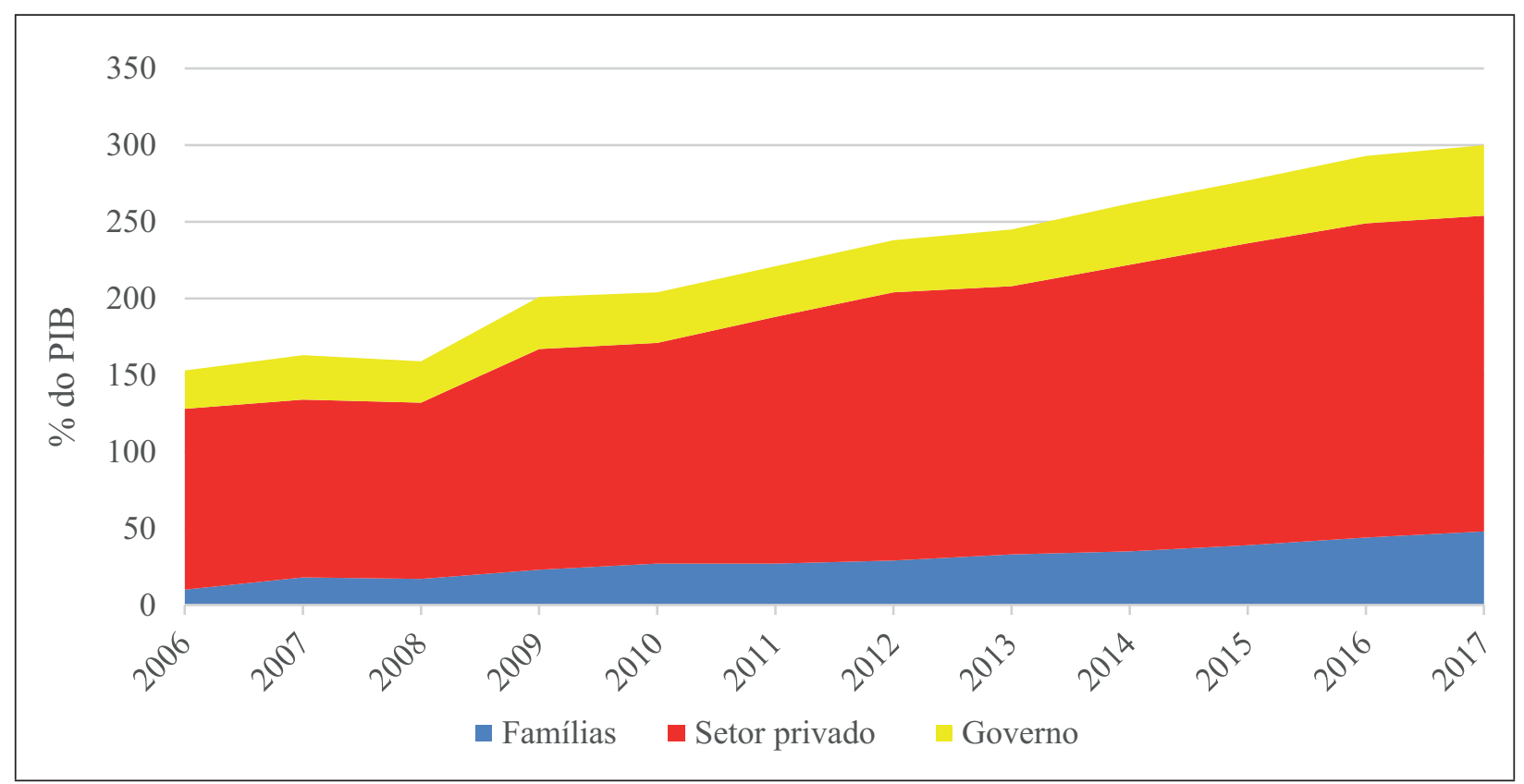

Fonte: Bank for International Settlements (2019).

O aumento das dívidas na China decorreu, principalmente, da elevação do endividamento do setor privado. A relativa estabilidade do setor público está ligada ao fato de que as políticas de estímulo fiscal e de aumento dos investimentos foram realizadas, em grande medida, por empresas estatais administradas pelos governos locais. É por isso que a dívida pública do setor governo chinês mantevese relativamente estável a partir da eclosão da crise global de 2008, enquanto, ao mesmo tempo, observou-se forte endividamento principalmente das empresas estatais controladas pelos governos locais. O endividamento das corporações, por exemplo, saltou de aproximadamente 115\% do PIB em 2008, para 206\% em 2017 (Bank for International Settlements 2019).

17 A dívida total inclui os débitos do setor público, instituições financeiras, corporações não-financeiras e as famílias. 
Por último, as políticas econômicas implementadas à medida que criaram distorções na alocação de recursos econômicos, reduziram a utilização da capacidade instalada e a elevação das dívidas contraídas resultaram em deterioração dos balanços financeiros, principalmente das empresas ${ }^{18}$ estatais chinesas. A perda de lucratividade das empresas estatais controladas pela State-owned Assets Supervision and Administration Commission of the State Council (SASAC) da China pode ser observada a partir dos dados contidos na Tabela 3.

Tabela 3. Balanço financeiro das empresas estatais chinesas controladas pela SASAC

\begin{tabular}{ccccc}
\hline Ano & $\begin{array}{c}\text { Lucro } \\
\text { (em bilhões de } \\
\text { renminbi) }\end{array}$ & $\begin{array}{c}\text { Ativos } \\
\text { (em bilhões de } \\
\text { renminbi) }\end{array}$ & $\begin{array}{c}\text { Retorno sobre } \\
\text { os ativos } \\
\text { (ROE) }\end{array}$ & $\begin{array}{c}\text { Dívidas/ativos } \\
(\%)\end{array}$ \\
\hline 2005 & 641 & 10.630 & 6.0 & 56.1 \\
2006 & 765 & 12.192 & 6.3 & 55.8 \\
2007 & 997 & 14.927 & 6.7 & 55.7 \\
2008 & 696 & 17.629 & 3.9 & 58.4 \\
2009 & 815 & 21.058 & 3.9 & 60.1 \\
2010 & 1.143 & 24.427 & 4.7 & 60.8 \\
2011 & 1.266 & 28.036 & 4.5 & 62.1 \\
2012 & 1.300 & 31.357 & 4.1 & 62.7 \\
2013 & 1.300 & 35.017 & 3.7 & 63.4 \\
2014 & 1.400 & 38.669 & 3.6 & 63.0 \\
2015 & 1.167 & 47.581 & 2.5 & 66.7 \\
2016 & 1.233 & 50.500 & 2.4 & 66.7 \\
2017 & 1.423 & 54.500 & 2.6 & 66.3 \\
\hline
\end{tabular}

Fonte: Lardy (2019).

Apesar do aumento dos ativos financeiros a partir de 2005, é possível observar que: (1) apesar do aumento dos lucros nominais, os ativos administrados pelas empresas estatais tiveram uma elevação proporcionalmente significativamente maior; (2) a perda de rentabilidade das empresas estatais pode ser observada por meio da redução dos retornos sobre os ativos a partir de 2008, e (3) houve um aumento proporcionalmente maior das dívidas em relação aos ativos das empresas estatais. O endividamento das empresas estatais já é $50 \%$ superior, em comparação

18 A SASAC é uma comissão (que caracteriza-se em uma espécie de holding) criada pelo governo central da China para controlar as empresas estatais. Em 2010, a SASAC tinha o controle direto e indireto de aproximadamente 23.378 empresas. Quando incluído as empresas subsidiárias, a SASAC controla ao redor de $60 \%$ das empresas estatais chinesas - excluída as empresas do setor financeiro. 
às corporações privadas. Antes da eclosão da crise global de 2008, o endividamento das empresas estatais e privadas era semelhante. Não por acaso, aproximadamente $75 \%$ do aumento do endividamento das empresas chinesas, a partir de 2009, decorrem de dívidas contraídas por parte de empresas estatais (Lardy 2019).

A canalização e direcionamento das políticas de crédito e subsídios para o setor estatal possuem, também, implicações para a própria produtividade da economia chinesa. Wei, Xie e Zhang (2017), ao comparar o desempenho das empresas estatais e privadas no tocante a questões relacionadas a processos de inovação produtiva (inovação tecnológica, registro de patentes), observam que, apesar de receberem proporcionalmente menos subsídios, as empresas privadas exibem maiores níveis de inovação produtiva. Ou seja, observou-se um aumento das disparidades de produtividade entre as empresas públicas e privadas da China, principalmente a partir da eclosão da crise global de 2008, com reflexos negativos para a própria Produtividade Total dos Fatores (TPF) ${ }^{19}$ no conjunto da economia chinesa. Esses indicadores podem ser observados a partir da Figura 4, que demonstra a evolução da TPF na China. A TPF teve um crescimento mais acelerado principalmente ao longo da década de 2000, o que corrobora com a perspectiva de que, após a crise global de 2008, o principal vetor do crescimento da China passou a ser o aumento do estoque de capital, em detrimento de ganhos de eficiência e alocação dos fatores econômicos.

Figura 4. Evolução da Produtividade Total dos Fatores da China $(2011=1)$

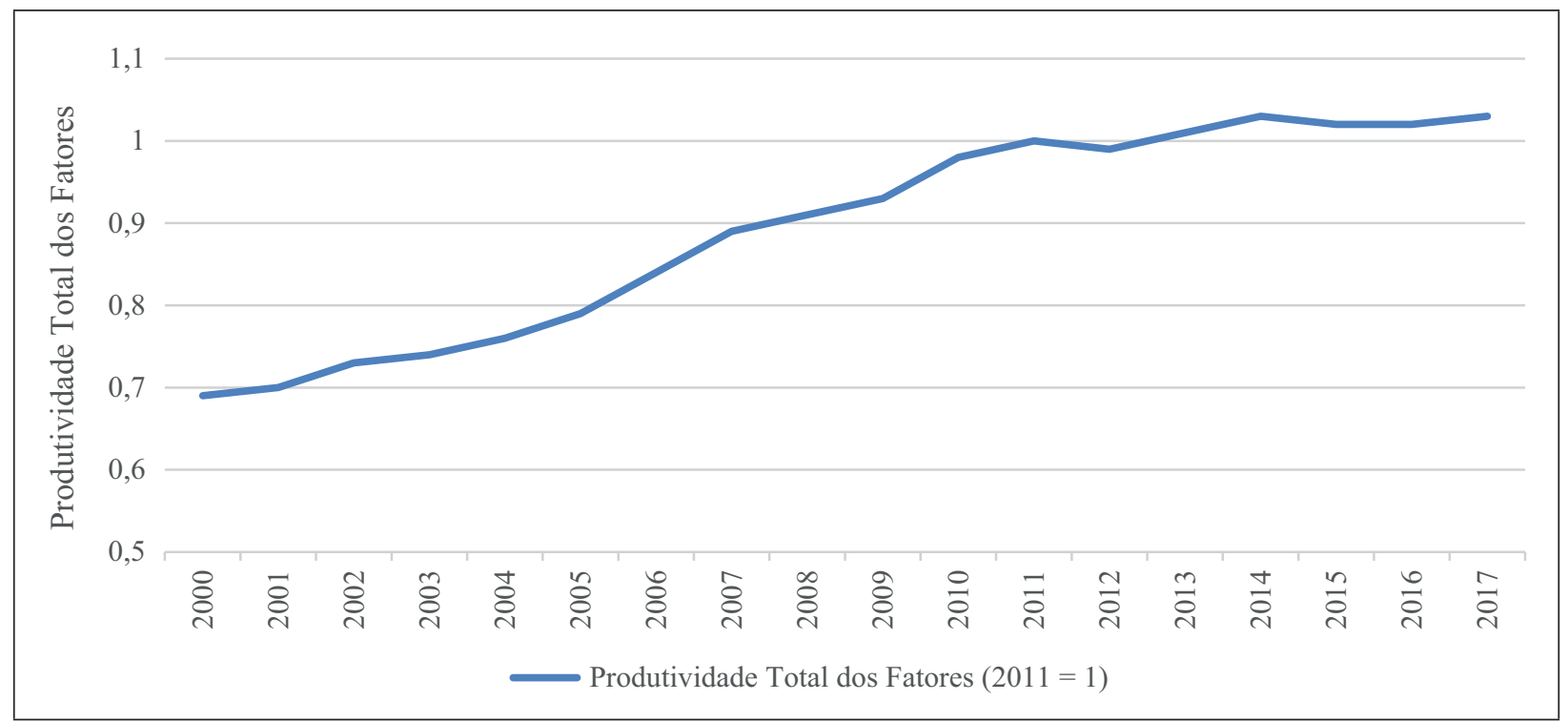

Fonte: University of Groningen and University of California (2020).

19 A PTF é o principal indicador para mensurar o nível de eficiência de um país na alocação dos fatores de produção. Não indica o nível de complexidade ou de estrutura produtiva, mas a eficiência na alocação dos fatores de produção. 
Por um lado, as políticas fiscais expansionistas e o afrouxamento monetário suavizaram os impactos negativos da crise global de 2008 sobre a economia da China. Ao canalizar a redução da demanda externa para a realização de investimentos domésticos, a economia chinesa conseguiu manter os níveis de demanda suficientes para permitir uma expansão do crescimento do PIB a taxas próximas dos parâmetros do "novo normal". Contudo, essas medidas culminaram no aprofundamento dos desequilíbrios macroeconômicos ao longo da década de 2010: desequilíbrios entre consumo, poupança e investimento; excesso de ociosidade da capacidade instalada; substancial aumento das dívidas nacionais; perda de eficiência na alocação de fatores de produção e relativa estagnação da produtividade econômica. Como observa Kroeber (2016, 210, tradução nossa), essas variáveis serão decisivas para o desempenho da economia da China nos próximos anos:

A China enfrenta, sem dúvidas, seu maior desafio em comparação a qualquer outro que já teve que superar em passado recente. Esse desafio é passar de um modelo de crescimento econômico baseado principalmente na mobilização de recursos para outro, baseado na eficiência do uso dos recursos econômicos. Dito de outra forma, a China passou as últimas três décadas investindo nos ativos necessários para se transformar em uma economia moderna. Agora, seu trabalho é maximizar o retorno desses ativos e investimentos ${ }^{20}$.

\section{A Era Xi Jinping e os limites da transição da economia da China para um "novo normal” no século 21}

Quando ascendeu ao cargo de presidente da China, em março de 2013, Jin Xinping, tinha como principal objetivo continuar o processo de transição da economia chinesa para um novo normal, com a equalização dos desequilíbrios macroeconômicos da década de 2010. As próprias lideranças do Partido Comunista da China já eram cientes da necessidade da transição do modelo de crescimento econômico chinês em direção a uma economia mais eficiente na alocação dos fatores de produção e com maior capacidade no desenvolvimento de novas tecnologias

20 China face a challenge arguably greater than any it has had to overcome in the past. This challenge is to shift away from a growth model based mainly on the mobilization of resources to one based mainly on the efficiency of resource use. Another way of putting it is that China has spent the last three decades instablling the assets needed for a modern economy. Now its job is to maximize the return on those assets. 
disruptivas, da Quarta Revolução Industrial no século 21. A preocupação por parte do novo governo de Xi Jinping, acerca da necessidade da combinação desses dois fatores (eficiência econômica e desenvolvimento tecnológico) como condições imprescindíveis para a continuidade do processo de convergência de renda com o mundo desenvolvido, ficou evidenciada a partir da análise dos objetivos contidos no décimo terceiro plano quinquenal lançado em 2015 (2016-2020)21.

Um dos pontos nevrálgicos analisados foi a adoção de políticas que resultem na equalização dos desequilíbrios macroeconômicos e reduzam a dependência de novos investimentos para sustentar a taxa de crescimento econômico chinesa Nesse contexto, as políticas implementadas devem incentivar o aumento do consumo doméstico em detrimento da realização de novos investimentos que exacerbem o descasamento entre oferta e demanda, principalmente no setor industrial, e reduzir a interferência política nos processos decisórios das empresas estatais chinesas para evitar a má alocação de recursos econômicos como ocorreu em muitos casos a partir da eclosão da crise global de 2008 (Economy 2018).

Além da equalização dos desequilíbrios macroeconômicos e da melhoria da eficiência na alocação dos fatores de produção, as autoridades chinesas elencaram uma série de estratégias para reduzir o gap tecnológico da China em setores tradicionais e transformar o país em um dos principais detentores das tecnologias disruptivas da Quarta Revolução Industrial. Na visão das autoridades chinesas, a inovação tecnológica passa a ser elemento essencial para a ascensão produtiva da China na produção de bens e serviços de maior valor agregado nas Cadeias Globais. Para isso, o governo chinês anunciou um plano de investimento em Pesquisa \& Desenvolvimento em áreas críticas, tais como: energia limpa, big data, segurança cibernética, inteligência artificial e tecnologia militar. Muitas dessas áreas, já contavam com pesados investimentos governamentais, mas o Plano Quinquenal de 2015 elevou as metas estipuladas para gastos na área de Pesquisa e Desenvolvimento e em setores considerados estratégicos pelas lideranças políticas da China.

O Plano quinquenal delineou também outros objetivos elencados como prioritários para o governo chinês, que convergem com a perspectiva de uma economia menos regulada por parte de Pequim. Destacam-se entre essas medidas:

21 Os planos quinquenais são um série de iniciativas lançadas pelo partido comunista chinês que visam delinear e descrever os principais objetivos socioeconômicos do país a cada cinco anos. O primeiro plano quinquenal foi lançado para cobrir o período (1953-1957), ainda na China comunista. 
continuidade das políticas de combate a corrupção no próprio país e dentro do partido comunista; aumento da transparência das leis e regras do país para investidores estrangeiros, redução da interferência do Banco Central da China na determinação da paridade do renminbi em relação ao dólar; gradual abertura da conta capital que permita maior conversibilidade da moeda chinesa; elevação dos gastos públicos com políticas sociais que aumentem o consumo doméstico; combate à desigualdade econômica principalmente entre as áreas rurais e urbanas; reversão da política de filho único implementada a partir do final da década de 1970 e redução das emissões de gases causadores do efeito estufa e da exploração nas florestas naturais (Minzner 2018).

Em certa medida, as intenções proclamadas pelo Plano Quinquenal de 2015 significam redução da intervenção do Estado chinês na economia e continuidade no processo de transição da China para uma economia de mercado. Contudo, até o presente momento, as políticas adotadas pelo governo de Xi Jinping têm ido, em muitos casos, na direção oposta em várias dimensões: a liberdade de expressão diminui e o controle estatal da Internet se acentua cada vez mais; o combate a corrupção tem sido continuado, mas as garantias de devido processo legal dos acusados são praticamente inexistentes; existe uma tendência para a concentração pessoal do poder em Xi Jinping que, em alguns aspectos, se aproxima perigosamente da era de Mao; e, adotou-se uma política agressiva nas disputas territoriais do Mar da China Meridional e na guerra cibernética com os Estados Unidos.

No campo econômico, as medidas proclamadas pelo governo Xi Jinping têm sido muito mais tímidas do que o anunciado e, em grande medida, reforçam o status quo do modelo de crescimento econômico adotado a partir da crise global de 2008. Nesse sentido, as reformas implementadas nos últimos anos pelo governo chinês baseiam-se mais em mudanças marginais do que propriamente transformações do sistema econômico da China. Na prática, observou-se continuidade das políticas anteriores à eclosão da crise global de 2008. Nas palavras de Economy (2018, 119-120, tradução nossa):

Em vez de avançar com as reformas necessárias para obter maior eficiência, produtividade e racionalidade na alocação de capital, Pequim decidiu traçar um caminho menos ambicioso. O resultado, após quatro anos de reformas econômicas, é um setor estatal que continua a registrar um aumento dos estoques de dívidas, consome crédito valioso e gera novos empregos. É um modelo que favorece as mega fusões e a capacidade de competição 
das empresas estatais no exterior, mas que, ao mesmo tempo, não resulta em uma política de maior abertura e competição nos mercados domésticos ${ }^{22}$.

Mesmo que tradicionalmente o timing histórico das reformas econômicas da China seja mais gradual e lento, observa-se perda de ímpeto por parte das lideranças chinesas na realização de reformas econômicas. Esse cenário fica mais evidente ao se comparar o ritmo das reformas econômicas da década de 1990, quando houve maciça transferência de ativos públicos para o setor privado e a China adequou-se, por exemplo, às exigências para entrar na OMC (Lardy 2014).

A contradição entre discurso e prática fica evidenciada a partir das medidas econômicas adotadas pelo governo da China. O excesso de capacidade no setor industrial chinês, por exemplo, é em parte decorrente dos investimentos realizados pelas próprias empresas estatais chinesas. Apenas na indústria do aço e carvão, onde existe importante participação de empresas estatais, a redução da produção para níveis que acompanhem a demanda resultará no corte de 4 milhões de empregos ou $0.5 \%$ da força de trabalho chinesa. Assim, as autoridades chinesas têm adotado posições mais cautelosas e de longo prazo na resolução dos desequilíbrios macroeconômicos que afligem a economia da China, mas que possam ter reflexos negativos para as lideranças políticas de Pequim. (Feldstein 2016).

Nesse cenário, a opção pela manutenção das atuais políticas que tendem a exacerbar os desequilíbrios macroeconômicos sugere que os fatores que levam as autoridades chinesas a serem mais conservadoras em relação à realização de reformas econômicas são múltiplos e ligados a questões de natureza política, econômica, social ou mesmo ideológica. Do ponto de vista político, as próprias lideranças chinesas, a partir do próprio Xi Jinping, percebem que, apesar dos riscos associados ao surgimento dos desequilíbrios macroeconômicos, é preferível manter a economia chinesa sob controle estatal. Ou seja, as lideranças chinesas têm optado por um modelo denominado pelas próprias lideranças como "socialismo com características chinesas”. O aprofundamento das reformas econômicas implica maior risco de instabilidade social em virtude dos possíveis impactos negativos que as reformas econômicas possam ter sobre o aumento do desemprego, à medida que as reformas econômicas reduzam os empregos nas empresas estatais. Uma política de contração mais radical do crédito afetará diretamente as empresas

22 Instead of pushing foward with the reforms necessary to realize greater efficiency, productivity, and rationality in the allocation of capital, Beijing has elected to chart a less ambitious course, The result after four years of economic reform is a state sector that continues to incur ever-higher levels of debt, consume valuable credit, and provide new Jobs. It is a course that favors mega-mergers to support SOEs' ability to compete abroad but not open to the door for greater competition at home. 
estatais pertencentes aos governos locais que apresentam maiores níveis de endividamento e fragilidade financeira. Por último, persistem focos de resistência na própria burocracia das empresas estatais ligadas à estrutura de poder do próprio Partido Comunista. Existe forte relação entre as lideranças políticas chinesas e a própria burocracia das empresas estatais que organizam lobbies na estrutura do Partido Comunista para impedir a adoção de medidas econômicas que possam reduzir subsídios e acesso a crédito preferencial destinados às empresas estatais da China.

A histórica relação entre a expansão da classe média e a demanda por participação política parece encontrar limites na China, que devem ser necessariamente reconhecidos hoje: uma China próspera e poderosa, que se mantém autoritária, é uma possibilidade significativa nas próximas décadas. No caso chinês, a tecnoburocracia estatal e o Partido Comunista (fortemente imbricados) são os principais adversários da transição democrática e eles têm conseguido muito sucesso em associar a nova classe empresarial privada ao regime autoritário. Deste modo, vastos setores da economia de mercado não demandam aumento do pluralismo político, diferentemente do que aconteceu na história de quase todo o mundo. Além disso, na China, o Estado sempre desempenhou um papel muito mais forte do que a sociedade civil, diferentemente dos Estados Unidos e de boa parte da Europa, onde a sociedade civil foi formada antes mesmo da criação do Estado nacional. Como o Partido Comunista teme um aumento, mesmo que limitado, do pluralismo político, avança de modo tímido com as reformas econômicas que poderiam ter consequências para o empoderamento de uma classe média e empresarial demandante de liberdades políticas e econômicas.

Para compensar a erosão de legitimidade da elite comunista, fortemente baseada em alto crescimento econômico, a saída parece ser continuar crescendo via capitalismo de Estado, com maior concentração nos gastos militares e avançar para uma política mais confrontacional com os Estados Unidos e o mundo democrático em geral. Muito diferente da lógica da União Soviética, exaurida em sua competição com o Ocidente pela alta proporção do complexo militar-industrial na economia (gastos em defesa de aproximadamente $20 \%$ do PIB na década de 1980), a lógica da China tem espaço para gigantesca expansão dos gastos militares e para um aumento do poder do complexo militar/industrial/cibernético. Assim, o "novo normal” está chegando menos normal do que seria necessário e isso tende a obstaculizar o futuro do crescimento econômico da China em virtude da contenção dos ímpetos reformistas que reduzem a capacidade de ação e controle do Partido Comunista sobre a economia chinesa. 


\section{Referências}

Amsden, Alice H. 2003. A ascensão do "resto". Os desafios ao ocidente de economias com industrialização tardia. São Paulo: Fundação Editora da Unesp.

Babones, Salvatore. 2011. The Middling Kingdom. Foreign Affairs, (September/October).

Banco Mundial. 2019. The World Bank Data. Disponível em: < https://data.worldbank. org/country/china >. Acesso: 15 ago. 2019.

Bank for International Settlements. 2019. BIS Statistics Explorer. Disponível em: < https://stats.bis.org/statx/toc/CRE.html >. Acesso: 20 abr. 2019.

Câmara de Comércio da União Europeia na China. 2016. Overcapacity in China. An Impediment to the Party's Reform Agenda. 2016. Disponível em: < www.european chamber.com.cn > . Acesso: 20 mar. 2018.

Canuto, Otaviano. 2010. "Recoupling or Switchover? Developing Countries in the Global Economy”. In The day after tomorrow, 31-50. Washington: World Bank.

Chen, Zhiwu. 2015. China's Dangerous Debt.Why the Economy Could Be Headed for Trouble. Foreign Affairs, Vol. 94, No. 3 (May/June).

Economy, Elizabeth C. 2018. The third revolution. Xi Jinping and the new Chinese state. Oxford: Oxford University Press.

Eichengreen, Barry; Park, Donghyun; Shin, Kwanho. 2011. Growth Slowdown Redux: New evidence on Middle - Economic Trap. Washington: National Bureau of Economic Statistics (NBER Working Paper No. 18673).

Feldstein, Martin. China's next agenda. 2016. Project Syndicate, march 29. Disponível em: < https://www.project-syndicate.org/commentary/china-growth-through-promarket-reforms-by-martin-feldstein-2016-03 > . Acesso: 02 abr. 2019.

Ferguson, Niall; Schularick, Moritz. The End of Chimerica. 2009. Washington: Harvard Business School, 2009. (Working Paper 10-037).

Ferguson, Niall; Schularick, Moritz. 2007. 'Chimerica' and the Global Asset Market Boom. International Finance, 10:3, pp. 215-239.

Fundo Monetário Internacional. 2019a. World Economic Outlook Database. Disponível em: < https://www.imf.org/external/pubs/ft/weo/2019/01/weodata/index.aspx > . Acesso: 10 ago. 2019.

Fundo Monetário Internacional. 2019b. Global Manufacturing Downturn, Rising Trade Barriers. Washington: FMI.

Fundo Monetário Internacional. 2015. Staff Report for the 2015 Article IV Consultation. Washington: IMF (IMF Country Report n. 15/234).

Kroeber, Arthur R. 2016. China's economy. What everyone needs to know. Oxford: Oxford University Press. 
Lardy, Nicholas R. 2019. The state strikes back. The end of economic reform in China? Washington: Peterson Institute for International Economics.

Lardy, Nicholas R. 2014. Markets over Mao. The rise of private business in China. Washington: Peterson Institute for International Economics.

Lardy, Nicholas R. 2012. Sustaining China’s Economic Growth After the Global Financial Crisis. Washington: Peterson Institute for International Economics.

Manzi, Rafael Henrique Dias. 2019. Economic globalization in the global post-crisis of 2008: limits and deadlocks. Brazil. J. Polit. Econ. [online], vol. 39, n. 3, pp. 470-484. Doi: https://doi.org/10.1590/0101-35172019-2922.

Mckay, Huw; Song, Ligang. 2012. "Rebalacing the Chinese Economy to Sustain Long-Term Growth”. In Rebalancing and Sustaining Growth in China, 1-18. Camberrra: The Australian National University.

Mckinsey Global Institute. 2015. Debt and (not much) deleveraging. London: Mckinsey \& Company.

Morris, Charles R. 2009. O Crash de 2008. Dinheiro Fácil, apostas arriscadas e o colapso global do crédito. São Paulo: Quatro Edições Ltda.

Minzner, Carl. 2018. End of an Era. How China’s Authoritarian Revival is Undermining its Rise. Oxford: Oxford University Press.

Roach, Stephen S. 2015. China's Complexity Problem. Project Syndicate, August 30. Disponível em: < http://www.project-syndicate.org/commentary/china-complexityproblem-by-stephen-s--roach-2015-08 > . Acesso: 05 abr. 2018.

Sharma, Ruchir. 2016. The rise and fall of Nations. Forces of change in the post-crisis world. New York: W. W. Norton \& Company Ltd.

Summers, Larry H. 2016. The Age of Secular Stagnation. Foreign Affairs (march/april). United States Census Bureau. Population. 2018. Disponível em: < http://www.census.gov/ > . Acesso: 13 abr. 2018.

University of Groningen University of California. 2020. Total Factor Productivity at Constant National Prices for China [RTFPNACNA632NRUG], retrieved from FRED, Federal Reserve Bank of St. Louis. Disponível em: < https://fred.stlouisfed.org/series/ RTFPNACNA632NRUG > . Acesso: 20. Mar. 2020.

Wei, Shang-Jin; Xie, Zhuan; Zhang, Xiaobo. 2017. “China's Transittion to a More Innovative Economy: Progress and Challenges”. In China's New sources of Economic Growth, 173-211. Acton: Australian National University.

Zhu, X. 2012. Understanding China's Growth: Past, Present, and Future”, Journal of Economic Perspectives, 26(4): 103-24. 